\title{
Serotonergic modulation of face-emotion recognition
}

\author{
C.M. Del-Ben, C.A.Q. Ferreira, W.C. Alves-Neto and F.G. Graeff \\ Divisão de Psiquiatria, Departamento de Neurologia, Psiquiatria e Psicologia Médica, Faculdade de \\ Medicina de Ribeirão Preto, Universidade de São Paulo, Ribeirão Preto, SP, Brasil \\ Correspondence to: C.M. Del-Ben, Departamento de Neurologia, Psiquiatria e Psicologia Médica, FMRP, \\ USP, Av. Bandeirantes, 3900, 14048-900 Ribeirão Preto, SP, Brasil \\ Fax: +55-16-3602-2544. E-mail: delben@fmrp.usp.br
}

\begin{abstract}
Facial expressions of basic emotions have been widely used to investigate the neural substrates of emotion processing, but little is known about the exact meaning of subjective changes provoked by perceiving facial expressions. Our assumption was that fearful faces would be related to the processing of potential threats, whereas angry faces would be related to the processing of proximal threats. Experimental studies have suggested that serotonin modulates the brain processes underlying defensive responses to environmental threats, facilitating risk assessment behavior elicited by potential threats and inhibiting fight or flight responses to proximal threats. In order to test these predictions about the relationship between fearful and angry faces and defensive behaviors, we carried out a review of the literature about the effects of pharmacological probes that affect 5-HTmediated neurotransmission on the perception of emotional faces. The hypothesis that angry faces would be processed as a proximal threat and that, as a consequence, their recognition would be impaired by an increase in 5-HT function was not supported by the results reviewed. In contrast, most of the studies that evaluated the behavioral effects of serotonin challenges showed that increased 5-HT neurotransmission facilitates the recognition of fearful faces, whereas its decrease impairs the same performance. These results agree with the hypothesis that fearful faces are processed as potential threats and that $5-\mathrm{HT}$ enhances this brain processing.
\end{abstract}

Key words: Facial expressions; Serotonin; Defensive behavior

Publication supported by FAPESP.

Received August 23, 2007. Accepted February 7, 2008

\section{Introduction}

Anxiety disorders have been related to abnormalities in brain processes underlying defensive responses to environmental threats $(1,2)$. The neurotransmitter serotonin (5hydroxytryptamine, 5-HT) seems to play a significant role in modulating defensive behavior. For instance, it has been suggested that 5 -HT would facilitate risk-assessment behavior elicited by a potential threat, which has been related to anxiety, by acting on the amygdala. In turn, 5-HT would inhibit fight or flight reactions to a proximal threat related to panic by acting on the midbrain periaqueductal gray matter $(3,4)$. Later, McNaughton and Corr (5) argued that two defense systems - an approach defense system that deals with potential threats and approach- avoidance conflict and is related to anxiety, and an avoidance defense system that commands withdrawal from a distal threat (related to fear) and proximal danger (related to panic) - are longitudinally distributed along the brain, although the former is largely represented in the forebrain and the latter in the hindbrain. In this view, the hypothesis cited above on the dual role of 5-HT in defense was preserved, with the approach defense system being stimulated and the avoidance defense system being inhibited by $5-\mathrm{HT}$.

The ability to identify facial expressions of emotion is important for social functioning and adaptation, and its study may contribute to the knowledge of the neurobiology of emotions. Neuroimaging studies have provided substantial data about the neural substrate of emotional face 
recognition. The amygdala has been consistently activated by the perception of fearful faces (6-9), although it can also be activated by other kinds of facial expressions, such as disgust $(7,10)$, sadness $(11,12)$, happiness $(9,11)$, and anger $(8,9,13)$. However, in direct contrast, activations of the amygdala in response to fearful faces were greater than in response to angry faces (8). The orbitofrontal cortex (Brodman area $=47$ ) also seems to be a common brain region involved in the processing of different emotional faces (10).

To understand the functional meaning of the brain activation patterns depicted by neuroimaging evidence, it would be necessary to know the adaptive meaning of each facial expression, which is by no means an easy task. Considering the processing of anxiety and related emotions, the facial expressions of fear and anger are likely to be of particular interest. It has been proposed that faces expressing fear could be considered to be an ambiguous stimulus (14), warning other people about a potential threat in the environment. On the other hand, an angry face directed toward a particular individual may represent a proximal threat. If these assumptions are true, the above mentioned hypothesis of a dual role of $5-\mathrm{HT}$ in defense allows the following predictions: 1) increased 5-HT function should facilitate the identification of fearful faces, whereas reduced 5-HT function should impair the same process; 2) increased 5-HT should impair, whereas lack of 5-HT should enhance, the identification of angry faces.

In order to test these predictions, we carried out a review of the literature about the effects of pharmacological probes that affect 5-HT-mediated neurotransmission on the perception of fearful and angry faces. For comparison, drug effects on the perception of other emotions are also described.

\section{Review protocol}

A computer-based search of the literature indexed in MEDLINE was made using the key words: face(s), facial, expression, emotion, and serotonin, with no time limit. In the first section, we have focused our survey on studies that objectively measured the performance (accuracy and speed) of healthy volunteers in the recognition of the emotion portrayed in the facial expression, considering the effect of a serotonergic drug compared to placebo. In the second section, we have analyzed the results of neuroimaging studies, some of which include performance data that have been discussed in the preceding section.

We excluded studies that evaluated the performance of volunteers with current psychiatric disorders and studies that adopted faces to evaluate other cognitive func- tions, such as memory. The survey was complemented with the bibliography of the reviewed articles. For the discussion, some references outside the above criteria have also been included.

We selected 14 articles according to the criteria cited above. Of these, ten (15-24) evaluated the effects of acute manipulation of the 5-HT system. Three studies (25-27) evaluated the effects of sub-chronic or chronic treatment with 5-HT probes; one of them also included a noradrenergic drug (25). Finally, one study (28) determined both the immediate and four-day later effect of a single dose of ecstasy.

\section{Behavioral data}

The effects of serotonergic drugs on the identification of facial expressions are summarized in Table 1.

The reduction of brain serotonergic function induced by the acute intake of a mixture of essential amino acids free of tryptophan, the precursor of 5-HT synthesis, impaired the recognition of fearful facial expressions by healthy women, without any effect on other emotional faces or on male volunteers (20). The same effect occurred in s-carriers of the 5' promoter region (5-HTTLPR) of the serotonin transporter of both genders, but not in LL homozygotes (23). On the other hand, acute dietary supplementation with tryptophan increased the perception of facial expressions of happiness and fear in healthy female volunteers (15). Chronic supplementation with tryptophan (14 days) did not change the perception of fearful faces, but facilitated the perception of happy expressions and decreased the recognition of disgusted faces in female, but not in male volunteers (27).

In the same direction, acute intravenous administration of the selective serotonin reuptake inhibitor (SSRI) citalopram $(10 \mathrm{mg}$ ) facilitated the recognition of fearful and happy faces by women (21). More recently, a similar effect regarding fearful faces has been shown in both genders after a single oral dose of citalopram (20 mg) (17). In contrast, healthy female participants submitted to subchronic treatment (7 days) with oral citalopram (20 mg/ day) showed impairment of the perception of facial expressions of fear, anger and disgust compared to placebo (25). A further study by the same research group (26) confirmed the reduction of fearful faces recognition after a 7-day treatment with citalopram in both genders.

Euthymic women with a previous history of major depressive episodes recognized facial expressions of fear more easily than healthy women without a history of depression. The acute intravenous administration of citalopram $(10 \mathrm{mg})$ normalized the ability of the volunteers with past depressive episodes to recognize fearful faces and 
increased the capacity of women without previous depression to recognize the same emotion (16).

In a naturalistic study, the acute administration of 3,4methylenedioxymethamphetamine (MDMA, "ecstasy") to volunteers of both genders increased the perception of fearful expressions. However, after 4 days of drug withdrawal, the opposite effect was observed, i.e., a decrease in the recognition of fearful faces (28).

No effect of the $5-\mathrm{HT}_{3}$ antagonist ondansetron on the modulation of facial emotional expressions has been found (22).

It is important to highlight that most of the reviewed studies did not report changes in subjective feelings of anxiety during the experimental procedures with serotonergic challenges.

\section{Neuroimaging data}

Pharmacological functional magnetic resonance imaging has become a very useful technique for investigating the effects of drugs on brain metabolic activity through the changes in the blood oxygen level-dependent signal. Nevertheless, only a few studies have investigated the pharmacological modulation of the hemodynamic response to facial expressions so far. Neuroimaging results are summarized in Table 2.

In an unconscious perception paradigm, where the volunteers were asked just to make a gender categorization of faces, Cools et al. (18) observed that tryptophan depletion in healthy male volunteers enhanced amygdala activation in response to fearful faces compared to happy and neutral faces as a function of self-reported threat sensitivity measured by BIS/BAS scales. These scales have been developed to test the constructs of the behavioral inhibition system and behavioral activation system proposed by Gray and McNaughton (2).

In a similar paradigm of gender categorization, a single dose $(7.5 \mathrm{mg})$ of intravenous citalopram attenuated the hemodynamic response of the right amygdala and right orbitofrontal cortex to aversive (angry, disgusted and fear-

Table 1. Effects of serotonergic probes on the perception of basic emotional facial expressions by healthy volunteers.

\begin{tabular}{|c|c|c|c|c|c|c|c|}
\hline \multirow[t]{2}{*}{ Reference } & \multirow[t]{2}{*}{ Method } & \multicolumn{6}{|c|}{ Emotion } \\
\hline & & Happiness & Sadness & Anger & Fear & Disgust & Surprise \\
\hline Harmer et al. (20) & Tryptophan depletion; both genders & - & - & - & $\downarrow^{*}$ & - & - \\
\hline Marsh et al. (23) & Tryptophan depletion; both genders & - & - & - & $\downarrow^{* *}$ & - & - \\
\hline Attenburrow et al. (15) & Tryptophan supplementation; only females & $\uparrow$ & - & - & $\uparrow$ & - & - \\
\hline Murphy et al. (27) & $\begin{array}{l}\text { Tryptophan supplementation for } 14 \text { days; } \\
\text { both genders }\end{array}$ & $\uparrow^{*}$ & - & - & - & $\downarrow^{*}$ & - \\
\hline Harmer et al. (21) & Intravenous citalopram (10 mg); only females & $\uparrow$ & - & - & $\uparrow$ & - & Not evaluated \\
\hline Browning et al. (17) & $\begin{array}{l}\text { Single dose of oral citalopram }(20 \mathrm{mg}) \text {; both } \\
\text { genders }\end{array}$ & - & - & - & $\uparrow$ & - & - \\
\hline \multirow[t]{4}{*}{ Bhagwagar et al. (16) } & $\begin{array}{l}\text { Intravenous citalopram }(10 \mathrm{mg}) \text {; euthymic } \\
\text { females with or without a past history of major } \\
\text { depression }\end{array}$ & & & & & & \\
\hline & $\mathrm{MD}+$ placebo & - & - & - & $\uparrow$ & - & Not evaluated \\
\hline & MD + citalopram & - & - & - & - & - & \\
\hline & No MD + citalopram & - & - & - & $\uparrow$ & - & \\
\hline Harmer et al. (25) & Oral citalopram (20 mg) for 7 days; only females & - & - & $\downarrow$ & $\downarrow$ & $\downarrow$ & - \\
\hline Harmer et al. (26) & Oral citalopram (20 mg) for 7 days; both genders & - & - & - & $\downarrow$ & - & - \\
\hline Harmer et al. (22) & Ondansetron; both genders & - & - & - & - & - & - \\
\hline \multirow[t]{3}{*}{ Hoshi et al. (28) } & Ecstasy; both genders & & & & & & \\
\hline & Day 0 & - & - & - & $\uparrow$ & - & - \\
\hline & Day 4 & - & - & - & $\downarrow$ & - & - \\
\hline
\end{tabular}

$\uparrow=$ increase of the identification of the facial emotion (lower number of errors and/or lower response time) in comparison to placebo; $\downarrow=$ decrease of the identification of the facial emotion (higher number of errors and/or higher response time) in comparison to placebo; $-=$ no differences between groups; ${ }^{*}$ differences only among females; ${ }^{* *}$ significant only in s carriers. MD = major depression. 
ful) faces compared to neutral faces in male volunteers (19). Pretreatment with citalopram $(20 \mathrm{mg})$ for seven days attenuated amygdala activation to fearful faces compared to happy faces in volunteers of both genders (26).

In these neuroimaging studies, no drug effect was observed on the task performed during scanning or on subjective measures, except for a reduction of self-rated hostility perception and behavior, evaluated by the BussDurkee Hostility Inventory, which was reported after 7 days of oral citalopram (26).

More recently, van der Veen et al. (24) replicated in females the results obtained by Cools et al. (18), showing a significant correlation between threat sensitivity (BIS scale) and higher right amygdala activation by fearful faces in contrast to happy faces under tryptophan depletion. This study has also shown that the mood depression caused by tryptophan depletion in healthy females with a family history of depression was associated with impaired performance of gender categorization of negative facial expressions (fear, sadness and disgust) and with increased activation of the right amygdala.

\section{Conciliating the data from serotonergic challenges on facial emotional expressions}

Although their number is small, the articles reviewed here point to a serotonergic modulation of the identification of basic emotional facial expression by healthy volunteers. Also, the lack of effect on subjective anxiety suggests that the serotonergic modulation of facial expression processing can occur independently of changes in and/or conscious recognition of the feelings aroused by emotional faces.

The results obtained with drugs that interfere with serotonergic neurotransmission reinforce the role of 5-HT in the processing of anxiety and fear (3), since 9 of 11 studies that measured the behavioral effects of serotonergic probes found changes in the ability to identify fearful faces. In fact, in one study (22), the lack of effect could be hypothesized a priori since, according to the Deakin and Graeff's hypothesis (3) on the dual role of 5-HT in defense, the $5-\mathrm{HT}_{3}$ receptor is not supposed to modulate anxiety or fear processing. The processing of other emotions, such

Table 2. Effects of serotonergic probes on the BOLD-fMRI signal provoked by the perception of basic emotional facial expressions.

\begin{tabular}{|c|c|c|c|c|c|c|}
\hline & Sample & Study design & Drug & fMRI task & $\begin{array}{c}\text { Facial } \\
\text { expressions }\end{array}$ & $\begin{array}{l}\text { Modulation of brain } \\
\text { activation }\end{array}$ \\
\hline Cools et al. (18) & 12 male volunteers & $\begin{array}{l}\text { Double-blind; } \\
\text { Placebo-controlled; } \\
\text { Crossover design }\end{array}$ & $\begin{array}{l}\text { Tryptophan-depleting } \\
\text { drink } 5 \text { h prior to the } \\
\text { fMRI session }\end{array}$ & $\begin{array}{l}\text { Block design; } \\
\text { Ekman faces; } \\
\text { Gender categorization }\end{array}$ & $\begin{array}{l}\text { Fearful; } \\
\text { Happy; } \\
\text { Neutral }\end{array}$ & $\begin{array}{l}\uparrow \text { Amygdala (fearful \& } \\
\text { happy faces; fearful \& } \\
\text { neutral faces) in threat- } \\
\text { sensitive volunteers }\end{array}$ \\
\hline Del-Ben et al. (19) & 12 male volunteers & $\begin{array}{l}\text { Single-blind; } \\
\text { Placebo-controlled; } \\
\text { Crossover design }\end{array}$ & $\begin{array}{l}\text { Intravenous } \\
\text { citalopram ( } 7.5 \mathrm{mg} / \\
7.5 \mathrm{~min}) 1 \mathrm{~h} \text { prior to } \\
\text { the fMRI session }\end{array}$ & $\begin{array}{l}\text { Block design; } \\
\text { Ekman faces; } \\
\text { Gender categorization }\end{array}$ & $\begin{array}{l}\text { Aversive } \\
\text { (fearful, } \\
\text { angry \& } \\
\text { disgusted); } \\
\text { Neutral }\end{array}$ & $\begin{array}{l}\downarrow \text { Right OFC (BA47) and } \\
\text { right amygdala (aversive } \\
\& \text { neutral faces) }\end{array}$ \\
\hline Harmer et al. (26) & $\begin{array}{l}24 \text { volunteers } \\
\text { (14 females) }\end{array}$ & $\begin{array}{l}\text { Double-blind; } \\
\text { Placebo-controlled; } \\
\text { Between group } \\
\text { comparison }\end{array}$ & $\begin{array}{l}\text { Oral citalopram } \\
(20 \mathrm{mg}) 7 \text { days of } \\
\text { treatment }\end{array}$ & $\begin{array}{l}\text { Block design; } \\
\text { Ekman faces; } \\
\text { Gender categorization }\end{array}$ & $\begin{array}{l}\text { Fearful; } \\
\text { Happy }\end{array}$ & $\begin{array}{l}\downarrow \text { Amygdala (fearful \& } \\
\text { happy faces) }\end{array}$ \\
\hline $\begin{array}{l}\text { Van der Veen et al. } \\
\text { (24) }\end{array}$ & 33 female volunteers & $\begin{array}{l}\text { Double-blind; } \\
\text { Placebo-controlled; } \\
\text { Crossover design }\end{array}$ & $\begin{array}{l}\text { Tryptophan-depleting } \\
\text { drink } 5 \text { h prior to the } \\
\text { fMRI session }\end{array}$ & $\begin{array}{l}\text { Event-related design; } \\
\text { Ekman faces; } \\
\text { Intensity of emotional } \\
\text { expression; } \\
\text { Gender categorization }\end{array}$ & $\begin{array}{l}\text { Fearful; } \\
\text { Sad; } \\
\text { Disgusted; } \\
\text { Happy }\end{array}$ & $\begin{array}{l}\uparrow \text { Right amygdala } \\
\text { (fearful \& happy faces) } \\
\text { in threat-sensitive } \\
\text { volunteers; } \\
\uparrow \text { Right amygdala and } \\
\text { right ventromedial } \\
\text { prefrontal cortex in } \\
\text { volunteers with family } \\
\text { history of depression }\end{array}$ \\
\hline
\end{tabular}

$\uparrow=$ increase of the neuronal response by the serotonergic probe; $\downarrow=$ decrease of the neuronal response by the serotonergic probe. BOLD-fMRI = blood oxygen level-dependent-functional magnetic resonance imaging; OFC = orbitofrontal cortex. 
as happiness and disgust, also seems to be under the influence of the 5-HT system, although the results reported so far are less consistent.

Two studies $(20,27)$ suggested a sexual dimorphism in the 5-HT modulation of emotional processing since the effects of either tryptophan depletion or tryptophan supplementation were observed only in female volunteers. However, it is impossible to further explore this hypothesis, given that most of the studies carried out so far with serotonergic manipulation have included just females in their samples.

Although MDMA releases dopamine and noradrenaline, its main mechanism of action is by serotonergic neurotransmission, inhibiting $5-\mathrm{HT}$ reuptake in the neuron membrane and stimulating the release of $5-\mathrm{HT}$ stored in pre-synaptic vesicles (29). Moreover, MDMA decreases 5HT synthesis by means of tryptophan-hydroxylase inhibition, causing 5-HT depletion during the days following its administration. Correlating with these actions, in the results reviewed, MDMA facilitated the recognition of fearful faces after acute administration, whereas four days later the perception of fearful faces was impaired (29).

The effects of manipulation of the levels of tryptophan, the precursor of serotonin synthesis, in the diet show a similar pattern, at least in healthy female volunteers (15) and in volunteers of both genders carrying the s genotype of the serotonin transporter (23). Thus, intake of tryptophan, and the consequent increase in 5- $\mathrm{HT}$ availability have been shown to facilitate the identification of fearful faces $(15,23)$, whereas the decrease of $5-\mathrm{HT}$ function by tryptophan depletion impairs the identification of fear expressions (20).

Acute intravenous administration of citalopram has been shown to facilitate the perception of fearful faces (21), an effect similar to that of tryptophan intake and of acute administration of ecstasy, and opposite to that of tryptophan depletion and on the fourth day after ecstasy. Taken together, these data suggest that intravenous injection of citalopram increases 5-HT availability. The clinical efficacy of the SSRIs is attributed to enhanced serotonergic neurotransmission, which in turn depends on the desensitization of $5-\mathrm{HT}_{1 \mathrm{~A}}$ autosomal receptors occurring nearly two weeks after repeated daily administration of these drugs (30). In fact, the beginning of treatment with SSRIs is supposed to reduce $5-\mathrm{HT}$ function, a fact that may be associated with the worsening of anxiety symptoms commonly observed in clinical practice (31). In contrast, sub-chronic treatment with citalopram for 7 days has been shown to reduce the recognition of fearful faces (25). These results may be related to downstream neuroadaptive changes that occur with repeated administration of antide- pressants, such as the down-regulation of specific 5-HT receptors.

Experimental data have shown that, following the administration of SSRIs, there is a greater increase in extracellular $5-\mathrm{HT}$ in the raphe nuclei than in the cortex (32). Therefore, it is possible that a low acute dose of an SSRI would preferentially increase 5-HT concentration near the cell bodies of serotonergic neurons, reducing their firing rate due to the activation of somatodendritic autoreceptors (33) and, hence, decreasing 5-HT release and lower synaptic 5-HT concentration postsynaptically. On the other hand, microdialysis studies in animals have shown increases in cortical extracellular 5-HT following acute SSRI administration (34-36). Moreover, intravenous injection of low doses of citalopram in healthy volunteers has resulted in plasma cortisol and prolactin increases $(37,38)$, taken as an indirect measure of 5-HT function in the brain.

Reported neuroimaging results are more difficult to interpret since few published studies have evaluated the pharmacological modulation of hemodynamic responses provoked by facial expression recognition. Moreover, the differences in the features of the samples studied, in the procedure of image acquisition and analysis, and in the paradigms of psychological activation used impair the comparison of the results reported.

Although behavioral data showed that acute citalopram increased, while chronic citalopram decreased the identification of fearful faces, both the 7-day administration of citalopram (21) and the acute intravenous dose of citalopram (19) decreased amygdala activation in response to aversive faces, an opposite effect to that of tryptophan depletion $(18,24)$. Nevertheless, the effect of tryptophan depletion occurred only in threat-sensitive volunteers and therefore these seemingly contradictory results between behavioral and neuroimaging data may be due to the interference of personality traits with emotional processing.

Assuming a direct correlation between neuronal activation measured by functional magnetic resonance imaging and the performance of emotional face recognition, we would expect increased 5-HT function to enhance the hemodynamic response of the amygdala to fearful faces. However, the reported results have shown that increasing 5-HT availability with citalopram decreased $(19,21)$, whereas decreasing 5-HT with tryptophan depletion enhanced, amygdala activation $(18,24)$.

In seeming contrast to the above conclusion, clinical studies have pointed to higher activation of the amygdala by emotional facial expressions in anxiety-prone healthy volunteers (39) and in patients with anxiety disorders (40) than in controls, and there is evidence from studies with depressive patients that antidepressant treatment normal- 
izes the enhanced activation of the amygdala in response to negative faces $(41,42)$. Even so, reported data have shown that the changes in fearful face recognition caused by $5-\mathrm{HT}$ probes have not been associated with changes in subjective measures of anxiety. Hence, we do not know whether the improvement in the recognition of fearful faces is associated with higher levels of anxiety or whether its impairment is related to less subjective anxiety of the perceiving subject.

Another weakness is that there are important differences between the experimental paradigms of the neuroimaging studies reviewed above. For instance, while subchronic treatment with citalopram (21) has included volunteers of both genders, acute administration of citalopram (19) has been made only in male volunteers, and there is considerable evidence pointing to sexual dimorphism in emotional processing (43). Also, the features of the functional magnetic resonance imaging technique itself have to be taken into account when interpreting these results. In fact, the meaning of the recorded changes in the hemodynamic response of specific brain areas caused by pharmacological modulation of neuropsychological tasks is not straightforward. Increases in the blood oxygen level-dependent signal are thought to be an index of increased neuronal metabolism measured by oxygen consumption. The enhancement of neuronal metabolism caused by a

\section{References}

1. Blanchard DC, Griebel G, Blanchard RJ. The Mouse Defense Test Battery: pharmacological and behavioral assays for anxiety and panic. Eur J Pharmacol 2003; 463: 97-116.

2. Gray JA, McNaughton N. The neuropsychology of anxiety: an enquiry into the functions of the septo-hippocampal system. 2nd edn. Oxford: Oxford University Press; 2000.

3. Deakin JFW, Graeff FG. 5-HT and mechanisms of defence. J Psychopharmacol 1991; 5: 305-315.

4. Graeff FG, Guimaraes FS, De Andrade TG, Deakin JF. Role of 5-HT in stress, anxiety, and depression. Pharmacol Biochem Behav 1996; 54: 129-141.

5. McNaughton N, Corr PJ. A two-dimensional neuropsychology of defense: fear/anxiety and defensive distance. Neurosci Biobehav Rev 2004; 28: 285-305.

6. Breiter HC, Etcoff NL, Whalen PJ, Kennedy WA, Rauch SL, Buckner RL, et al. Response and habituation of the human amygdala during visual processing of facial expression. Neuron 1996; 17: 875-887.

7. Phillips ML, Young AW, Senior C, Brammer M, Andrew C, Calder AJ, et al. A specific neural substrate for perceiving facial expressions of disgust. Nature 1997; 389: 495-498.

8. Whalen PJ, Shin LM, Mclnerney SC, Fischer $\mathrm{H}$, Wright $\mathrm{Cl}$, Rauch SL. A functional MRI study of human amygdala responses to facial expressions of fear versus anger. Emotion 2001; 1: 70-83. pharmacological challenge can reflect both an improvement of the performance ("working better") and the need for an extra effort to achieve the same level of function ("working harder"). More studies correlating neuroimaging and performance data are needed to clarify this issue.

\section{Conclusion}

The behavioral data reviewed here indicate that increased 5-HT neurotransmission facilitates the recognition of fearful faces, whereas its decrease impairs the same performance, without a significant change in subjective anxiety. These results are in agreement with the hypothesis that fearful faces are processed as potential threats and that 5-HT facilitates such brain processing.

In contrast, the hypothesis that angry faces would be processed as a proximal threat and, as a consequence, their recognition would be impaired by an increase of 5-HT function was not supported by the results reviewed since only 1 of 10 studies with serotonergic probes found a significant drug effect on the perception of angry faces.

Finally, the neuroimaging results reported thus far on the effect of 5-HT probes on the brain processing of emotional face recognition are rather inconsistent, more studies being needed in this field.
9. Fitzgerald DA, Angstadt M, Jelsone LM, Nathan PJ, Phan $\mathrm{KL}$. Beyond threat: amygdala reactivity across multiple expressions of facial affect. Neuroimage 2006; 30: 1441-1448.

10. Sprengelmeyer R, Rausch M, Eysel UT, Przuntek H. Neural structures associated with recognition of facial expressions of basic emotions. Proc Biol Sci 1998; 265: 1927-1931.

11. Yang TT, Menon V, Eliez S, Blasey C, White CD, Reid AJ, et al. Amygdalar activation associated with positive and negative facial expressions. Neuroreport 2002; 13: 17371741.

12. Surguladze SA, Brammer MJ, Young AW, Andrew $C$, Travis MJ, Williams SC, et al. A preferential increase in the extrastriate response to signals of danger. Neuroimage 2003; 19: 1317-1328

13. Hariri AR, Bookheimer SY, Mazziotta JC. Modulating emotional responses: effects of a neocortical network on the limbic system. Neuroreport 2000; 11: 43-48.

14. Whalen PJ. Fear, vigilance, and ambiguity: initial neuroimaging studies of the human amygdala. Curr Dir Psychol Sci 1998; 7: 177-188.

15. Attenburrow MJ, Williams C, Odontiadis J, Reed A, Powell $\mathrm{J}$, Cowen PJ, et al. Acute administration of nutritionally sourced tryptophan increases fear recognition. Psychopharmacology 2003; 169: 104-107.

16. Bhagwagar Z, Cowen PJ, Goodwin GM, Harmer CJ. Nor- 
malization of enhanced fear recognition by acute SSRI treatment in subjects with a previous history of depression. Am J Psychiatry 2004; 161: 166-168.

17. Browning M, Reid C, Cowen PJ, Goodwin GM, Harmer CJ. A single dose of citalopram increases fear recognition in healthy subjects. J Psychopharmacol 2007; 21: 684-690.

18. Cools R, Calder AJ, Lawrence AD, Clark L, Bullmore E, Robbins TW. Individual differences in threat sensitivity predict serotonergic modulation of amygdala response to fearful faces. Psychopharmacology 2005; 180: 670-679.

19. Del-Ben CM, Deakin JF, McKie S, Delvai NA, Williams SR, Elliott $R$, et al. The effect of citalopram pretreatment on neuronal responses to neuropsychological tasks in normal volunteers: an FMRI study. Neuropsychopharmacology 2005; 30: 1724-1734

20. Harmer CJ, Rogers RD, Tunbridge E, Cowen PJ, Goodwin GM. Tryptophan depletion decreases the recognition of fear in female volunteers. Psychopharmacology 2003; 167: 411 417.

21. Harmer CJ, Bhagwagar Z, Perrett DI, Vollm BA, Cowen PJ, Goodwin GM. Acute SSRI administration affects the processing of social cues in healthy volunteers. Neuropsychopharmacology 2003; 28: 148-152.

22. Harmer CJ, Reid CB, Ray MK, Goodwin GM, Cowen PJ. $5 \mathrm{HT}(3)$ antagonism abolishes the emotion potentiated startle effect in humans. Psychopharmacology 2006; 186: 18-24.

23. Marsh AA, Finger EC, Buzas B, Soliman N, Richell RA, Vythilingham $M$, et al. Impaired recognition of fear facial expressions in 5-HTTLPR S-polymorphism carriers following tryptophan depletion. Psychopharmacology 2006; 189: 387-394.

24. van der Veen FM, Evers EA, Deutz NE, Schmitt JA. Effects of acute tryptophan depletion on mood and facial emotion perception related brain activation and performance in healthy women with and without a family history of depression. Neuropsychopharmacology 2007; 32: 216-224.

25. Harmer CJ, Shelley NC, Cowen PJ, Goodwin GM. Increased positive versus negative affective perception and memory in healthy volunteers following selective serotonin and norepinephrine reuptake inhibition. Am J Psychiatry 2004; 161: 1256-1263.

26. Harmer CJ, Mackay CE, Reid CB, Cowen PJ, Goodwin GM. Antidepressant drug treatment modifies the neural processing of nonconscious threat cues. Biol Psychiatry 2006; 59: 816-820.

27. Murphy SE, Longhitano C, Ayres RE, Cowen PJ, Harmer CJ. Tryptophan supplementation induces a positive bias in the processing of emotional material in healthy female volunteers. Psychopharmacology 2006; 187: 121-130.

28. Hoshi R, Bisla J, Curran HV. The acute and sub-acute effects of 'ecstasy' (MDMA) on processing of facial expressions: preliminary findings. Drug Alcohol Depend 2004; 76: 297-304.

29. Green AR, Cross AJ, Goodwin GM. Review of the pharmacology and clinical pharmacology of 3,4-methylenedioxy- methamphetamine (MDMA or "Ecstasy"). Psychopharmacology 1995; 119: 247-260.

30. Stahl SM. Mechanism of action of serotonin selective reuptake inhibitors. Serotonin receptors and pathways mediate therapeutic effects and side effects. J Affect Disord 1998; 51: 215-235

31. Kent JM, Coplan JD, Gorman JM. Clinical utility of the selective serotonin reuptake inhibitors in the spectrum of anxiety. Biol Psychiatry 1998; 44: 812-824.

32. Bel N, Artigas F. Fluvoxamine preferentially increases extracellular 5-hydroxytryptamine in the raphe nuclei: an in vivo microdialysis study. Eur J Pharmacol 1992; 229: 101103.

33. Gartside SE, Umbers V, Hajos M, Sharp T. Interaction between a selective 5-HT1A receptor antagonist and an SSRI in vivo: effects on 5-HT cell firing and extracellular 5HT. Br J Pharmacol 1995; 115: 1064-1070.

34. David DJ, Bourin M, Jego G, Przybylski C, Jolliet P, Gardier AM. Effects of acute treatment with paroxetine, citalopram and venlafaxine in vivo on noradrenaline and serotonin outflow: a microdialysis study in Swiss mice. Br J Pharmacol 2003; 140: 1128-1136.

35. Felton TM, Kang TB, Hjorth S, Auerbach SB. Effects of selective serotonin and serotonin/noradrenaline reuptake inhibitors on extracellular serotonin in rat diencephalon and frontal cortex. Naunyn Schmiedebergs Arch Pharmacol 2003; 367: 297-305

36. Moret C, Briley M. Effects of acute and repeated administration of citalopram on extracellular levels of serotonin in rat brain. Eur J Pharmacol 1996; 295: 189-197.

37. Attenburrow MJ, Mitter PR, Whale R, Terao T, Cowen PJ. Low-dose citalopram as a 5-HT neuroendocrine probe. Psychopharmacology 2001; 155: 323-326.

38. McKie S, Del-Ben C, Elliott R, Williams S, del Vai N, Anderson I, et al. Neuronal effects of acute citalopram detected by pharmacoMRI. Psychopharmacology 2005; 180: 680-686.

39. Stein MB, Simmons AN, Feinstein JS, Paulus MP. Increased amygdala and insula activation during emotion processing in anxiety-prone subjects. Am J Psychiatry 2007; 164: 318327.

40. Phan KL, Fitzgerald DA, Nathan PJ, Tancer ME. Association between amygdala hyperactivity to harsh faces and severity of social anxiety in generalized social phobia. Biol Psychiatry 2006; 59: 424-429.

41. Sheline YI, Barch DM, Donnelly JM, Ollinger JM, Snyder AZ, Mintun MA. Increased amygdala response to masked emotional faces in depressed subjects resolves with antidepressant treatment: an fMRI study. Biol Psychiatry 2001; 50: 651-658.

42. Fu CH, Williams SC, Cleare AJ, Brammer MJ, Walsh ND, $\mathrm{Kim} \mathrm{J}$, et al. Attenuation of the neural response to sad faces in major depression by antidepressant treatment: a prospective, event-related functional magnetic resonance imaging study. Arch Gen Psychiatry 2004; 61: 877-889.

43. Cahill L. Why sex matters for neuroscience. Nat Rev Neurosci 2006; 7: 477-484. 